\title{
Molecular Cloning, Chromosomal Localization, and Functional Characterization of a Human Liver $\mathrm{Na}^{+}$/ Bile Acid Cotransporter
}

\author{
Bruno Hagenbuch and Peter J. Meier \\ Division of Clinical Pharmacology and Toxicology, Department of Medicine, University Hospital, CH-8091 Zürich, Switzerland
}

\begin{abstract}
We have used a cDNA probe from a cloned rat liver $\mathrm{Na}^{+} /$taurocholate cotransporting polypeptide (Ntcp) to screen a human liver cDNA library. A 1,599-bp cDNA clone that encodes a human $\mathrm{Na}^{+}$/ taurocholate cotransporting polypeptide (NTCP) was isolated. The human NTCP consists of 349 amino acids (calculated molecular mass of $38 \mathrm{kD}$ ) and exhibits $77 \%$ amino acid homology with the rat $\mathrm{Ntcp}$. In vitro translation experiments indicate that the protein is glycosylated and has a molecular weight similar to the rat Ntcp. Injection of in vitro transcribed cRNA into Xenopus laevis oocytes resulted in the expression of $\mathrm{Na}^{+}$-dependent taurocholate uptake. Saturation kinetics indicated that the human NTCP has a higher affinity for taurocholate (apparent $K_{\mathrm{m}}=6 \mu \mathrm{M}$ ) than the previously cloned rat protein (apparent $K_{\mathrm{m}}=25 \mu \mathrm{M}$ ). NTCP-mediated taurocholate uptake into oocytes was inhibited by all major bile acid derivatives $(100 \mu \mathrm{M})$, bumetanide $(500 \mu \mathrm{M})$, and bromosulphophthalein $(100 \mu \mathrm{M})$. Southern blot analysis of genomic DNA from a panel of human/hamster somatic cell hybrids mapped the human NTCP gene to chromosome 14. (J. Clin. Invest. 1994. 93:1326-1331.) Key words: bile salts • hepatocytes • organic anion transport • sinusoidal • taurocholate
\end{abstract}

\section{Introduction}

Bile formation is an important function of hepatocytes and involves transport of bile acids and other organic anions from portal blood into bile. Conjugated bile acids such as taurocholate or glycocholate enter hepatocytes predominantly via a sodium-dependent cotransport system. Phenomenologicaly, this secondary active bile acid uptake system has been well characterized in a variety of experimental systems including the perfused rat liver, isolated rat hepatocytes, isolated rat, and human sinusoidal membrane vesicles and Xenopus laevis oocytes (15 ). Using functional expression cloning in Xenopus laevis oo-

\footnotetext{
Address correspondence to Bruno Hagenbuch, Ph.D., Division of Clinical Pharmacology and Toxicology, Department of Internal Medicine, University Hospital, CH-8091 Zürich, Switzerland.

Received for publication 27 July 1993 and in revised form 22 October 1993.
}

\author{
J. Clin. Invest. \\ (C) The American Society for Clinical Investigation, Inc. \\ 0021-9738/94/03/1326/06 \$2.00
}

Volume 93, March 1994, 1326-1331 cytes, a rat liver $\mathrm{Na}^{+}$-taurocholate cotransporting polypeptide (Ntcp) ${ }^{1}$ has been cloned (6). In this study, we have used an Ntcp-derived cDNA probe to screen a human liver cDNA library. We report the isolation and functional characterization of the human hepatocellular $\mathrm{Na}^{+}$-dependent taurocholate cotransporter and its chromosomal localization.

\section{Methods}

Cloning of a human $\mathrm{Na}^{+} /$bile acid cotransporter $\mathrm{cDNA}$. Total human liver RNA was prepared from pieces of frozen liver (obtained from kidney donors and kindly provided by U. A. Meyer, Biozentrum Basel, Switzerland ) using a single-step acid guanidinium thiocyanate-phenolchloroform extraction method (7). mRNA was isolated using oligo(dT)-cellulose chromatography (8). A cDNA library was constructed from total poly(A) ${ }^{+}$RNA (Superscript kit; Life Technologies, Inc., Gaithersburg, MD). The cDNA was unidirectionally ligated into NotI/Sal I cut pSPORT1, and recombinant plasmids were introduced into Escherichia coli WM1100 by electroporation (Gene Pulser; BioRad Laboratories, Hercules, CA). Replica filters containing $2 \times 10^{5}$ recombinants of the cDNA library were screened using an EcoRI fragment (nucleotides $261-1,187$ of the rat Ntcp cDNA) (6) that was labeled with $3,000 \mathrm{Ci} / \mathrm{mmol}\left[\alpha-{ }^{32} \mathrm{P}\right] \mathrm{dCTP}$ (Amersham International, Buckinghamshire, United Kingdom) using the Random Primed DNA Labeling Kit (Boehringer Mannheim GmbH, Mannheim, Germany). After $2 \mathrm{~h}$ of prehybridization at $42^{\circ} \mathrm{C}$ in $50 \%$ formamide, $0.75 \mathrm{M}$ $\mathrm{NaCl} / 0.075 \mathrm{M}$ sodium citrate at pH 7.0 ( $5 \times \mathrm{SSC}), 5 \times$ Denhardt's solution, $0.5 \%$ SDS, and $200 \mu \mathrm{g} / \mathrm{ml}$ of denatured salmon sperm DNA, the filters were hybridized for $16 \mathrm{~h}$ at $42^{\circ} \mathrm{C}$ in the same solution containing, in addition, the labeled probe $\left(2 \times 10^{6} \mathrm{cpm} / \mathrm{ml}\right)$. After hybridization, the filters were washed twice for $15 \mathrm{~min}$ at room temperature in $2 \times$ SSC, $0.1 \%$ SDS, followed by one wash for $1 \mathrm{~h}$ at $42^{\circ} \mathrm{C}$ in $1 \times \mathrm{SSC}$, $0.1 \% \mathrm{SDS}$, and one final wash for $15 \mathrm{~min}$ at $50^{\circ} \mathrm{C}$ in $0.1 \times \mathrm{SSC}, 0.1 \%$ SDS. Washed filters were exposed to $\mathrm{x}$-ray film at $-70^{\circ} \mathrm{C}$ overnight. After two rounds of screening, single positive colonies, which were functionally tested using Xenopus laevis oocytes, were obtained. $5 \mathrm{ng}$ of in vitro-transcribed cRNA were injected into Xenopus laevis oocytes and $\mathrm{Na}^{+}$-dependent taurocholate uptake was measured as described (5). Sequence analysis was performed using double-stranded cDNA as template and the T7 Sequencing kit (Pharmacia Biotech Inc., Piscataway, $\mathrm{NJ}$ ). Human liver $\mathrm{Na}^{+} /$taurocholate cotransporting polypeptide (NTCP) cDNA was sequenced in both directions using either unidirectionally deleted clones (Erase-a-base; Promega Corp., Madison, WI) or especially synthesized oligonucleotide primers. Nucleotide and amino acid sequence analyses were performed with the DNA and protein sequence analysis program DNASIS/PROSIS (Pharmacia Biotech Inc., Piscataway, NJ). Putative membrane spanning domains were de-

1. Abbreviations used in this paper: BSP, bromosulfophthalein; Ntcp, rat liver $\mathrm{Na}^{+}$/ taurocholate cotransporting polypeptide; NTCP, human liver $\mathrm{Na}^{+} /$taurocholate cotransporting polypeptide. 
termined according to Klein et al. (9). The GCG software package (Genetics Computer Group, Inc., Madison, WI) (10) was used to perform sequence comparison and multiple alignments.

Transport assays in oocytes. Oocytes were maintained in culture and uptake of $2.1 \mathrm{Ci} / \mathrm{mmol}\left[\mathrm{G}-{ }^{3} \mathrm{H}\right.$ ] taurocholic acid (Du Pont-New England Nuclear, Boston, MA) was determined as described (5).

Chromosomal localization of NTCP. Southern blots containing genomic DNA samples from 26 individual somatic cell hybrids digested with PstI were obtained from BIOS Corp. (New Haven, CT). After 1.5 $\mathrm{h}$ of prehybridization at $42^{\circ} \mathrm{C}$ in $50 \%$ formamide, $5 \times \mathrm{SSC}, 5 \times$ Denhardt's solution, $0.5 \% \mathrm{SDS}$, and $200 \mu \mathrm{g} / \mathrm{ml}$ of denatured salmon sperm DNA the filters were hybridized for $16 \mathrm{~h}$ at $42^{\circ} \mathrm{C}$ in the same solution containing, in addition, $2 \times 10^{6} \mathrm{cpm} / \mathrm{ml}$ of labeled probe (a PflMI/ EcoRI fragment corresponding to nucleotides -8 to 987 encompassing most of the coding region of NTCP). After hybridization, the filters were washed twice for $5 \mathrm{~min}$ at room temperature in $2 \times \mathrm{SSC}, 0.1 \%$ SDS, followed by one wash for $15 \mathrm{~min}$ at $63^{\circ} \mathrm{C}$ in $0.1 \times \mathrm{SSC}, 0.1 \% \mathrm{SDS}$. Filters were exposed to $\mathrm{x}$-ray film at $-70^{\circ} \mathrm{C}$.

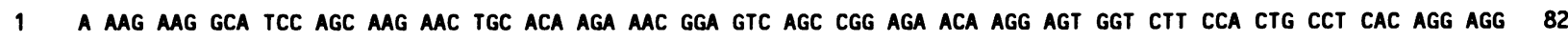

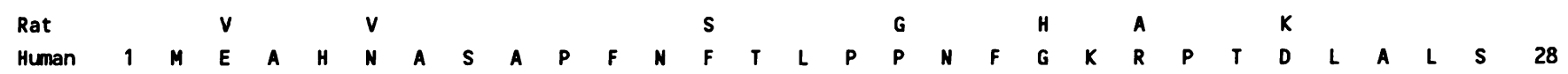
83 ATG GAG GCC CAC AAC GCG TCT GCC CCA TTC AAC TTC ACC CTG CCA CCC AAC TTT GGC AAG CGC CCC ACA GAC CTG GCA CTG AGC 166

Rat I L L L L

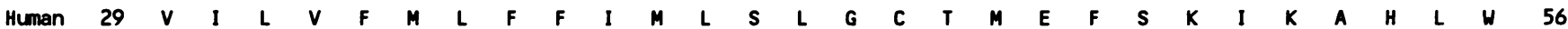
167 GTC ATC CTG GTG TTC ATG TTG TTC TTC ATC ATG CTC TCG CTG GGC TGC aCC aTG GAG TTC aGC aAg aTC aAg GCT CAC TTA TGG 250

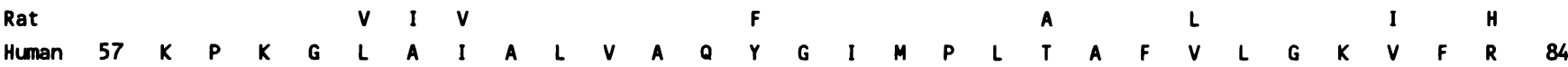
251 AAG CCT AAA GGG CTG GCC ATC GCC CTG GTG GCA CAG TAT GGC ATC ATG CCC CTC ACG GCC TIT GTG CTG GGC AAG GTC TTC CGG 334

Rat

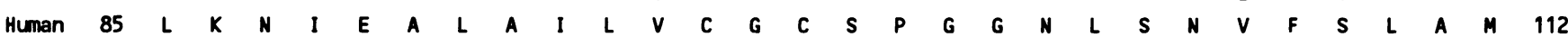
335 CTG AAG AAC ATT GAG GCA CTG GCC ATC TTG GTC TGT GGC TGC TCA CCT GGA GGG AAC CTG TCC AAT GTC TTC AGT CTG GCC ATG 418

Rat

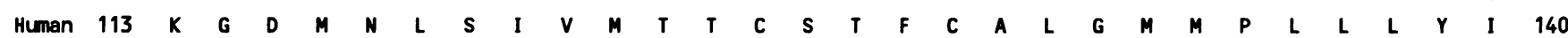
419 AAG GGG GAC ATG AAC CTC AGC ATT GTG ATG ACC ACC TGC TCC ACC TTC TGT GCC CTT GGC ATG ATG CCT CTC CTC CTG TAC ATC 502

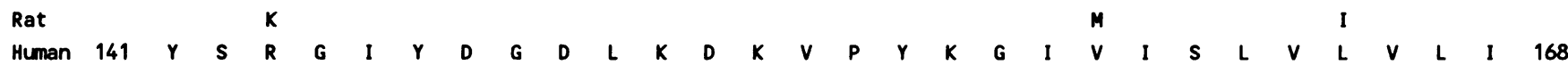
503 TAC TCC AGG GGG ATC TAT GAT GGG GAC CTG AAG GAC AAG GTG CCC TAT AAA GGC ATC GTG ATA TCA CTG GTC CTG GTT CTC ATT 586

Rat

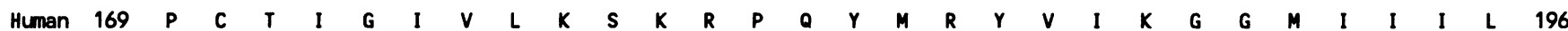
587 CCT TGC ACC ATA GGG ATC GTC CTC AAA TCC AAA CGG CCA CAA TAC ATG CGC TAT GTC ATC AAG GGA GGG ATG ATC ATC ATT CTC 670

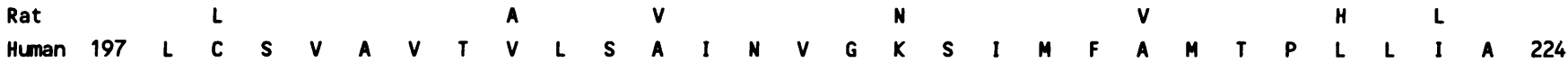
671 TTG TGC AGT GTG GCC GTC ACA GTT CTC TCT GCC ATC AAT GTG GGG AAG AGC ATC ATG TTT GCC ATG ACA CCA CTC TTG ATT GCC 754

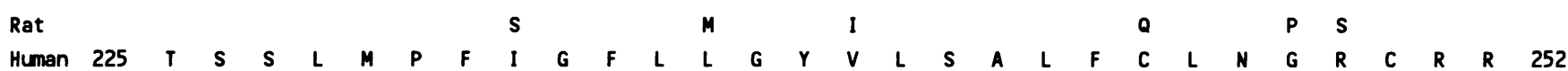
755 ACC TCC TCC CTG ATG CCT TTT ATT GGC TTT CTG CTG GGT TAT GTT CTC TCT GCT CTC TTC TGC CTC AAT GGA CGG TGC AGA CGC 838

Rat

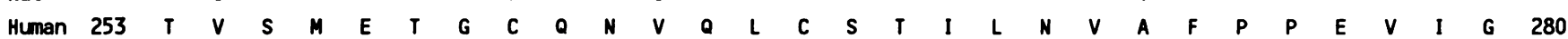
839 ACT GTC AGC ATG GAG ACT GGA TGC CAA AAT GTC CAA CTC TGT TCC ACC ATC CTC AAT GTG GCC TTT CCA CCT GAA GTC ATT GGA 922

Rat

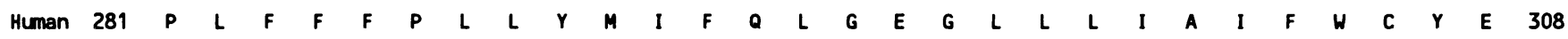
923 CCA CTT TTC TTC TIT CCC CTC CTC TAC ATG ATT ITC CAG CTT GGA GAA GGG CTT CTC CTC ATT GCC ATA TTT TGG TGC TAT GAG 1006

$\begin{array}{lllllllllllllll}\text { Rat } & I & P & Q & T & I & T & K & A & & D & A & T & A & E\end{array}$

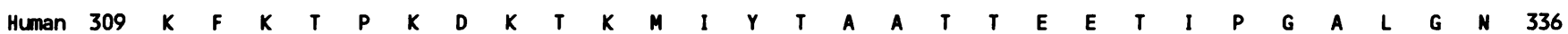
1007 AAA TTC AAG ACt CCC AAG GAT aAA ACA AAA ATG ATC TAC ACA GCT GCC ACA ACT GAA GAA ACA ATt CCA GGA GCT CTG GGA AAT 1090

Rat

Human 337 G $T$ T $Y$ Y $K$ G $G$ G

1091 GGC ACC TAC AAA GGG GAG GAC TGC TCC CCT TGC ACA GCC TAG CCC TTC CCC TGG TGG CCT GGA TTC TGG TCC CAA AGC AAT TCT 1174 1175 GAA AGC CAG TGT GGT AAA CTA GAG AGA GCA GCA AAA ACA CCA GTC TTG CCT GAG TCT TTC TCC AGC ATT TCC AGT ACA TCT ATC 1258 1259 AGA ATC ATC AAG TCT TGG CCG GGA ACA CAG ACA GGG TGT CTA CCC AAG AAG CCT CAC CTA TCC CCA ACT TAG AAT ITG CTA CTT 1342 1343 ATT TTA AAG ACT TGT TCA GTG ACT GTA AAC TCT ATG AAA CCA GAA ACC GAA TCT GCC TCT TGC TGG GAT CTC TAA AAG TGT CTG 1426 1427 ATA AGC ATC TTA AAG TCA CTC AAT TCC TGA ACT AAT CAA TAT ATA TGT TTA ACC CAT TAC TCA AAT ACC CAA ATC CCA TTC CAA 1510 1511 GTT ITG TGA CCC AAA AGA GAA ATA AAT GCT CAC AAG TGC TGT AGA ATT AAA CTT CAG AAG TTC TAA CCT TAA AAA AAA AAA AAA 1594 1595 AAA AA

1599

Figure 1. Nucleotide and deduced amino acid sequences of NTCP cDNA. Amino acid residues that differ between the human and the rat protein are shown above the amino acid sequence. (The sequence reported in this paper has been submitted to the GenBank Data Bank with the accession number L21893.) 


\section{Results and Discussion}

Nucleotide and amino acid sequences of NTCP. To clone the NTCP, we screened $\sim 200,000$ colonies of a cDNA library prepared from human liver poly $(\mathrm{A})^{+}$RNA using as a probe a ${ }^{32} \mathrm{P}$-labeled EcoRI fragment complementary to the major part of the coding region of the rat Ntcp cDNA (6). After two rounds of screening, five single clones were identified. cDNA sequence analysis revealed that four of them were identical. mRNA was synthesized in vitro from these four clones and injected into Xenopus laevis oocytes. Indeed, all four cRNAs led to the expression of $\mathrm{Na}^{+}$-dependent taurocholate uptake. One of these functionally active clones was sequenced and the cDNA and deduced amino acid sequences are shown in Fig. 1. The total cDNA insert of the human NTCP consists of 1,599 nucleotides. Starting with the initiation site at nucleotide 83 , an open reading frame extends over the next 1,047 nucleotides coding for a protein of 349 amino acids with a calculated molecular mass of $\sim 38 \mathrm{kD}$. Although the presence of a polyadenylation signal $\sim 40$ bases upstream of the poly(A) tail together with hybridization of the cDNA to a $1.6-\mathrm{kb}$ human liver mRNA on a Northern blot (data not shown) indicate the isolation of a full-length clone, additional primer extension experiments shall reveal the location of the cap site and thus establish the real length of the $5^{\prime}$ untranslated sequence. The amino acid sequence of the human and the rat $\mathrm{Na}^{+} /$bile acid cotransporters is compared in Figs. 1 and 2. There is $88 \%$ similarity between the human and the rat amino acid sequences, $77 \%$ of the residues being identical and another $11 \%$ being conservative replacements. Whether the clustering of nonconservative amino acid replacements at the $\mathrm{COOH}$-terminal end of the protein has any functional significance is not yet known. At the DNA level, the lowest identities were found within the 5'-noncoding region $(70 \%)$ and the highest identities within the coding and the 3 '-noncoding regions ( $83 \%$ ). The overall identity of only $78 \%$ with the rat cDNA explains the weak signal previously obtained on Northern blots $(6,11)$. Based on hydrophobicity analysis (9) and in analogy to the rat Ntcp, we propose the secondary structure model with seven transmembrane domains as depicted in Fig. 2. In vitro translation experiments performed as described $(6)$ resulted in the synthesis of an unglycosylated $34-\mathrm{kD}$ polypeptide on SDS-PAGE in the absence of a glycosylated $40-\mathrm{kD}$ polypeptide in the presence of dog pancreatic microsomes (data not shown ). The 6-kD difference is compatible with two sites being glycosylated. Experiments using site-directed mutagenesis to determine the natural glycosylation sites of the rat Ntcp revealed that Asn 5 and Asn 11 of the rat protein are glycosylated (Hagenbuch, B., and P. J. Meier, manuscript in preparation). In addition, immunostaining of primary rat hepatocytes with a polyclonal antibody against the $\mathrm{COOH}$-terminal end of the rat Ntcp was only achieved in the presence of detergents, suggesting an intracellular localization of the $\mathrm{COOH}$-terminal domain (unpublished observation). These data support the predicted model shown in Fig. 2, but additional experiments are required to definitively determine the exact location of all cytoplasmic loops and of the number

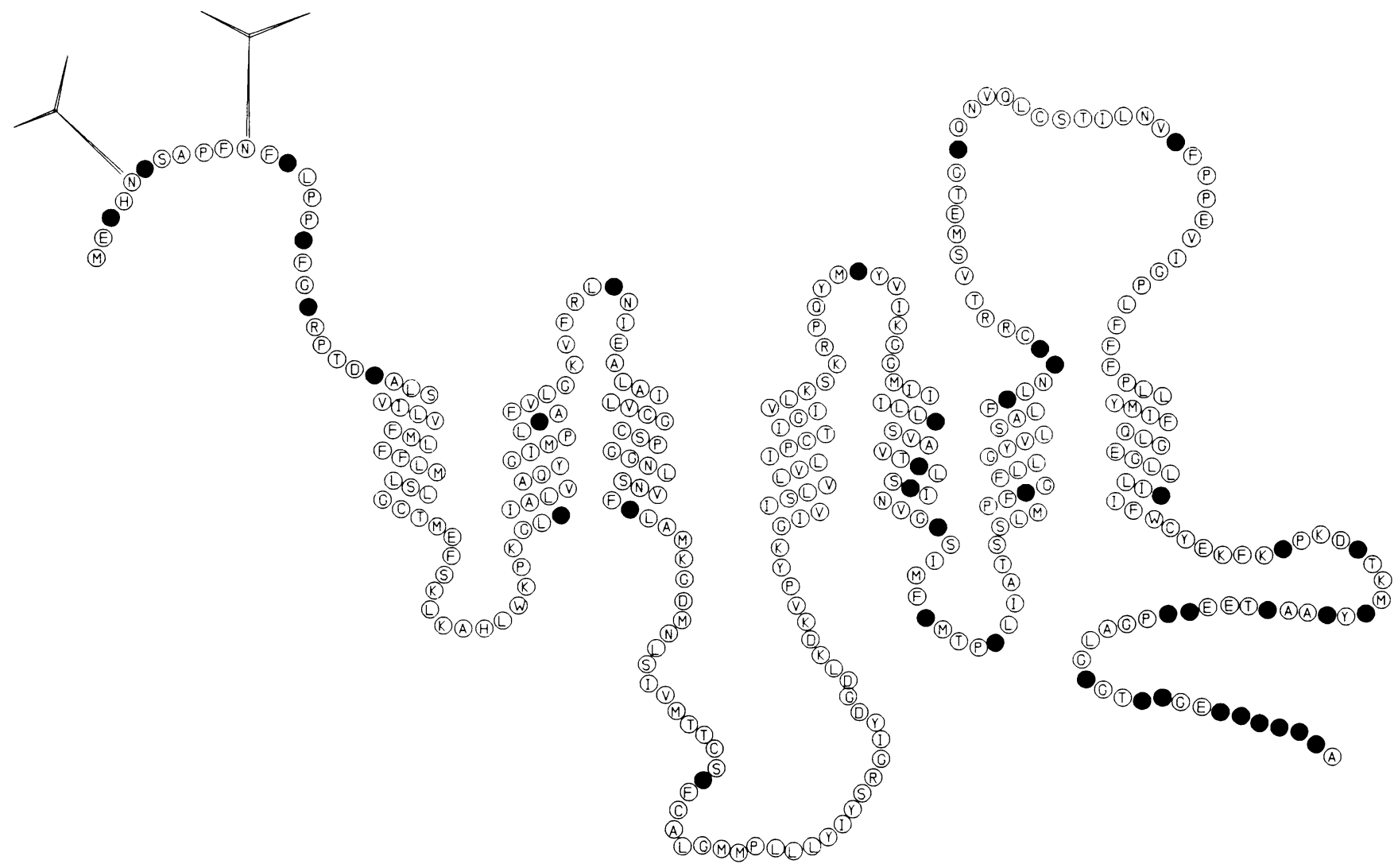

Figure 2. Proposed secondary structure model of the human NTCP. The protein is depicted with seven transmembrane segments (see text) of 21 residues each. Glycosylation at Asn5 and Asn 11 is indicated. Closed circles, nonconservative amino acid replacements between the human and the rat transporters. 
and location of the transmembrane domains. The differences in the amino acid sequence between the human and the rat $\mathrm{Na}^{+} /$bile acid cotransporting polypeptides together with their different affinities for taurocholate ( see below) might be a good starting point for mutational analysis to define functionally important amino acids (Fig. 2, closed circles).

Functional characterization of NTCP. As demonstrated in Fig. 3, injection of $5 \mathrm{ng}$ of NTCP-cRNA resulted in $\mathrm{Na}^{+}$-dependent taurocholate uptake that was $\sim 20$-fold above the background of noninjected oocytes. Interestingly, injection of the same amount of rat Ntcp-cRNA resulted in $\sim 10$-fold higher expression of $\mathrm{Na}^{+}$-dependent taurocholate uptake, suggesting that the human transporter might exhibit a much lower bile acid transport capacity as compared to the rat system. Alternatively, the expression of the human NTCP-cRNA may be less efficient in oocytes as compared to the rat Ntcp-cRNA, as it was also the case for the human and rabbit intestinal $\mathrm{Na}^{+}$-dependent glucose cotransporters $(12,13)$ and the human and canine cardiac $\mathrm{Na}^{+} / \mathrm{Ca}^{2+}$ exchangers $(14,15)$.

To further characterize the human NTCP, we next investigated its transport kinetics and its substrate specificity. As demonstrated in Fig. 4, the cloned human $\mathrm{Na}^{+} /$bile acid cotransport system showed clear saturability with an apparent $K_{\mathrm{m}}$ for taurocholate of $6.3 \pm 2.4 \mu \mathrm{M}$. This value is significantly lower than the previously reported $25 \mu \mathrm{M}$ for the rat transporter (6). This higher affinity of the human NTCP would allow more efficient extraction of bile acids at low plasma concentrations and might help to keep the human systemic bile acid concentrations at the known physiological low levels (16).

To compare the substrate inhibition pattern of NTCP with the rat Ntcp, as well as with reported studies performed with human basolateral membrane vesicles (3), we measured $\mathrm{Na}^{+}$dependent taurocholate uptake into oocytes in the presence of the major bile acid derivatives and some other organic anions. Table I summarizes these inhibition studies and demonstrates

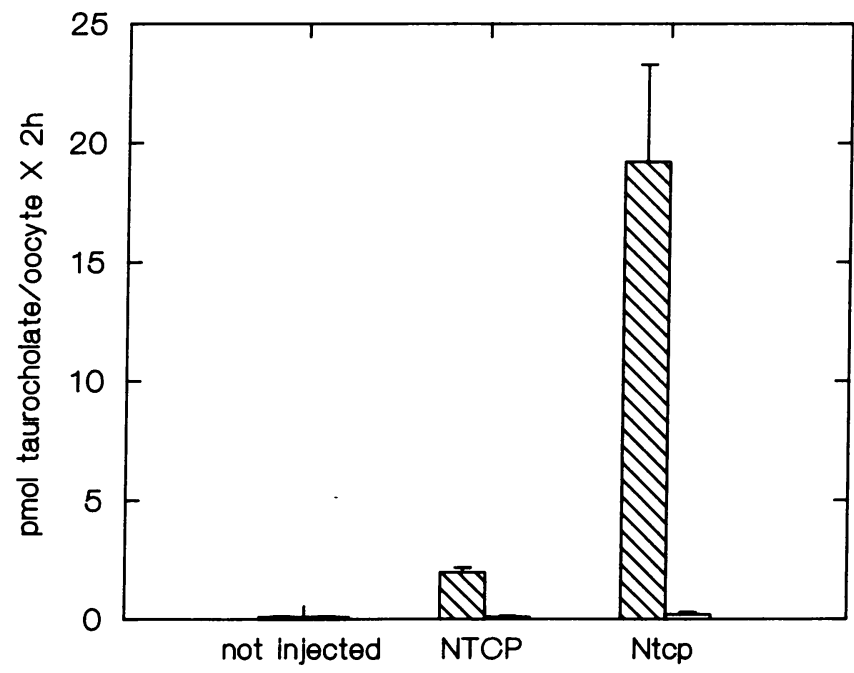

Figure 3. Functional expression of NTCP cRNA in oocytes. Xenopus laevis oocytes were either not injected or were injected with $5 \mathrm{ng}$ of in vitro synthesized human $(N T C P)$ or rat $(N t c p)$ cRNA. Oocytes were cultured for $2 \mathrm{~d}$ and 2-h taurocholate $(17 \mu \mathrm{M})$ uptake values were determined in the presence of either $100 \mathrm{mM} \mathrm{NaCl}$ (hatched bars) or choline chloride (open bars) as described (5). Values represent mean \pm SE of 12-15 determinations in one of four oocyte preparations.

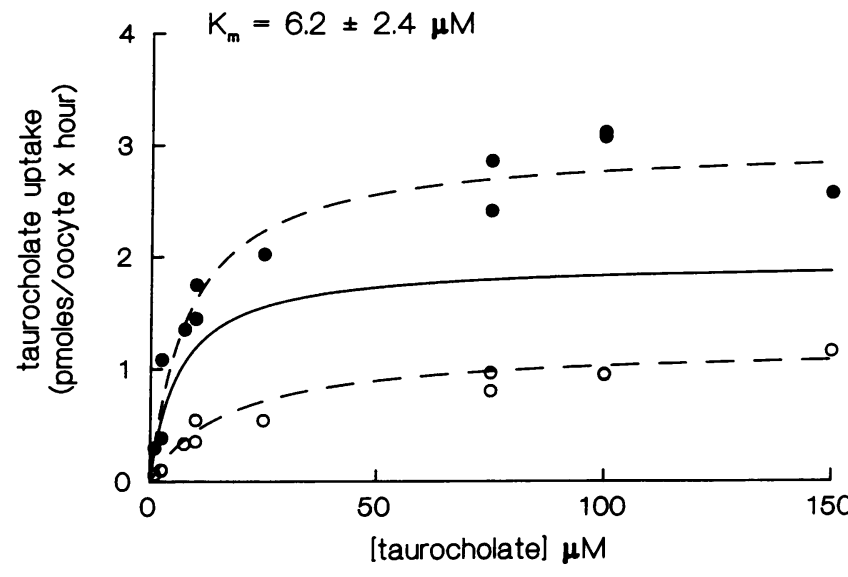

Figure 4. Kinetics of taurocholate uptake by NTCP cRNA-injected oocytes. Xenopus laevis oocytes were injected with $5 \mathrm{ng}$ of cRNA. After $2 \mathrm{~d}$ in culture, 1-h uptake of taurocholate $(2.5-150 \mu \mathrm{M})$ was determined. Values represent means of 12-15 determination from two out of three experiments performed with different batches of oocytes. $\mathrm{Na}^{+}$-dependent taurocholate transport was calculated as the difference between the uptake in the presence of $100 \mathrm{mM} \mathrm{NaCl}$ (closed circles) and uptake in the presence of $100 \mathrm{mM}$ choline chloride (open circles). The curves were fitted by nonlinear regression analysis assuming Michaelis-Menten kinetics.

that similar to previous observations for the rat Ntcp (6) and experiments in intact hepatocytes (17) the synthetic keto-bile acid taurodehydrocholate had no inhibitory effects. All major physiological bile acids on the other hand inhibited the cloned human NTCP by $40-90 \%$. Unconjugated bile acids exhibited a less pronounced inhibition as compared to the taurine or glycine conjugates with the exception of chenodeoxycholate

Table I. Effect of Various Organic Anions on $\mathrm{Na}^{+}$-dependent Taurocholate Uptake into NTCP-cRNA-Injected Oocytes

\begin{tabular}{lcc}
\hline \multicolumn{1}{c}{ Inhibitor } & $\begin{array}{c}\text { Taurocholate uptake } \\
\text { (mean } \pm \text { SE) }\end{array}$ & $\begin{array}{c}\text { Percent of } \\
\text { control }\end{array}$ \\
\hline Nonel/oocyte per $h$ & \\
Taurodehydrocholate & $1.175 \pm 0.114$ & $100 \pm 10$ \\
Cholate & $1.066 \pm 0.080$ & $91 \pm 7$ \\
Taurocholate & $0.675 \pm 0.089$ & $57 \pm 8$ \\
Glycocholate & $0.351 \pm 0.036$ & $30 \pm 3$ \\
Chenodeoxycholate & $0.522 \pm 0.046$ & $44 \pm 4$ \\
Taurochenodeoxycholate & $0.156 \pm 0.022$ & $13 \pm 2$ \\
Glycochenodeoxycholate & $0.223 \pm 0.035$ & $19 \pm 2$ \\
Ursodeoxycholate & $0.161 \pm 0.020$ & $14 \pm 2$ \\
Tauroursodeoxycholate & $0.531 \pm 0.067$ & $45 \pm 6$ \\
Lithocholate & $0.090 \pm 0.010$ & $8 \pm 1$ \\
Taurolithocholate & $0.737 \pm 0.090$ & $63 \pm 8$ \\
Glycolithocholate & $0.389 \pm 0.073$ & $33 \pm 6$ \\
Taurodeoxycholate & $0.279 \pm 0.051$ & $24 \pm 4$ \\
Probenecid $(1 \mathrm{mM})$ & $0.116 \pm 0.009$ & $10 \pm 1$ \\
Bumetanide $(0.5 \mathrm{mM})$ & $1.194 \pm 0.152$ & $101 \pm 13$ \\
BSP $(0.1$ mM) & $0.831 \pm 0.087$ & $71 \pm 7$ \\
& $0.483 \pm 0.052$ & $41 \pm 4$ \\
\hline
\end{tabular}

Oocytes were injected with $5 \mathrm{ng}$ of NTCP-cRNA and then cultured for $3 \mathrm{~d}$. 1-h uptake of $10 \mu \mathrm{M}$ taurocholate was measured in the presence of $100 \mu \mathrm{M}$ bile acids or the indicated concentrations of other organic anions. 


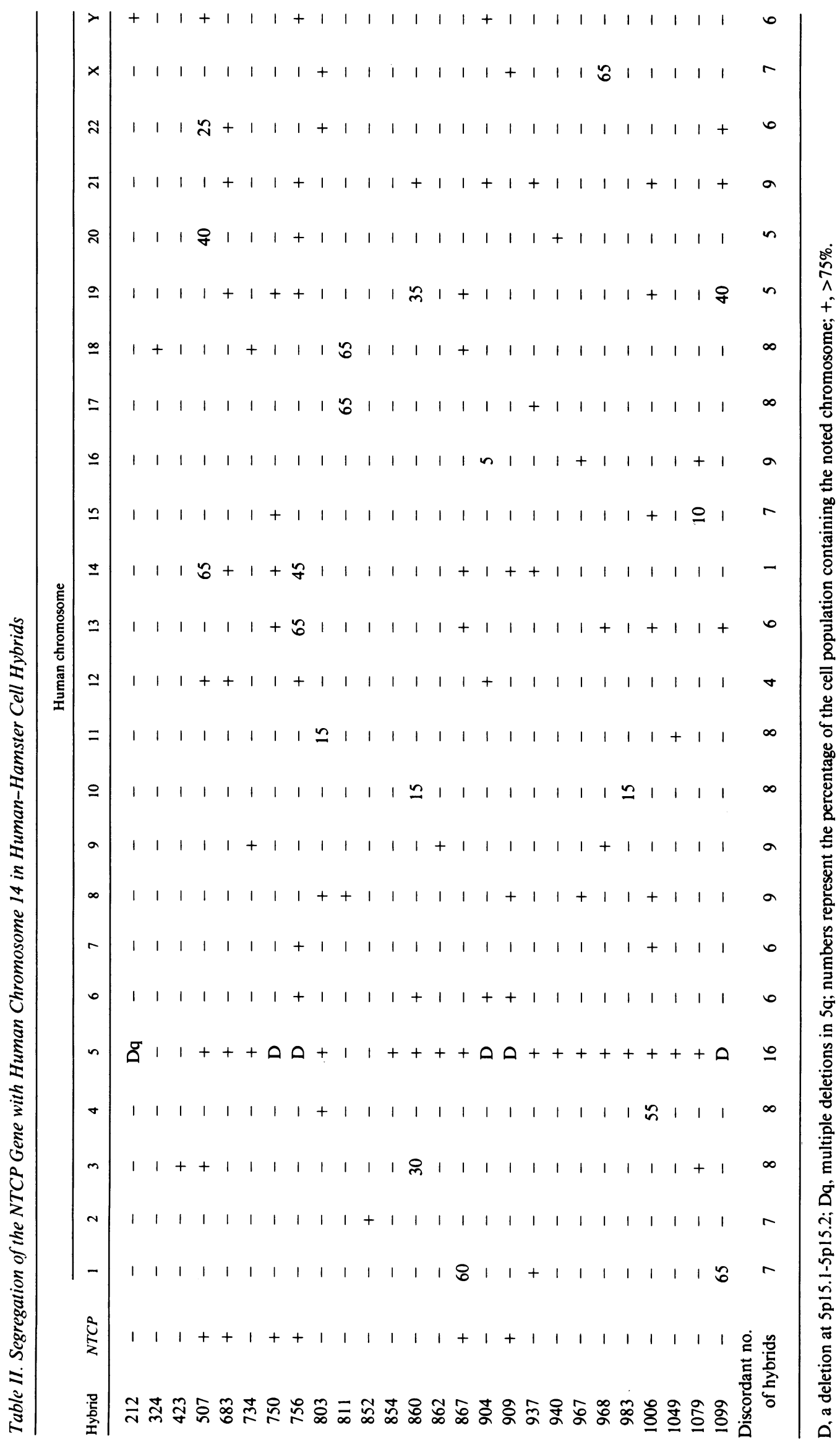


which was as potent an inhibitor as its taurine and glycine conjugates. Probenecid and bumetanide did not or only slightly inhibited NTCP mediated $\mathrm{Na}^{+}$-dependent taurocholate uptake, while bromosulfophthalein (BSP) exerted a stronger inhibitory effect. This cis-inhibition pattern of NTCP is similar to the one previously observed with rat Ntcp (6), which is also inhibited by BSP, but does not transport this nonbile acid organic anion (18). Whether or not the inhibitory conjugated bile acids are in fact transported by NTCP is currently under further investigation.

Chromosomal localization of NTCP. To determine the chromosomal location of the human NTCP gene, we used Southern blot analysis of a DNA panel of human-hamster somatic cell hybrids. PstI-digested DNA samples of 26 humanhamster cell hybrids were analyzed by hybridization with a PflMI/EcoRI fragment of the cloned human NTCP. The results of this hybridization analysis are summarized in Table II. Correlation of the presence of a human specific hybridization signal with the human chromosome content of the hybrid cell lines showed that the NTCP gene is located on chromosome 14. The single discordance with hybrid 937 could be explained by a possible small deletion of chromosome 14 in this hybrid, which is not detected in karyotype analysis.

In conclusion, we have cloned a human $\mathrm{Na}^{+} /$bile acid cotransporter that has a significantly higher affinity for taurocholate than the rat Ntcp. The protein showed a $77 \%$ amino acid homology to rat Ntcp and the gene could be localized to chromosome 14. These studies provide the basis for future investigation and characterization of the human NTCP gene in various physiological and pathophysiological situations.

\section{Acknowledgments}

We thank Prof. U. A. Meyer, Biozentrum Basel, Switzerland for supplying us with frozen human liver tissue, Ani Ohannessian for excellent technical assistance, and Prof. B. F. Scharschmidt for critical reading of the manuscript.

This study was supported by the Swiss National Science Foundation Grant 32-29878.90. Dr. Hagenbuch is a recipient of a Cloetta Foundation fellowship.

\section{References}

1. Van Dyke, R. W., J. E. Stephens, and B. F. Scharschmidt. 1982. Bile acid transport in cultured rat hepatocytes. Am. J. Physiol. 243:G484-G492.

2. Frimmer, M., and K. Ziegler. 1988. The transport of bile acids in liver cells. Biochim. Biophys. Acta. 947:75-99.

3. Novak, D. A., F. C. Ryckman, and F. J. Suchy. 1989. Taurocholate transport by basolateral plasma membrane vesicles isolated from human liver. Hepatology. 10:447-453.

4. Zimmerli, B., J. Valantinas, and P. J. Meier. 1989. Multispecificity of $\mathrm{Na}^{+}$-dependent taurocholate uptake in basolateral (sinusoidal) rat liver plasma membrane vesicles. J. Pharmacol. Exp. Ther. 250:301-308.

5. Hagenbuch, B., H. Lübbert, B. Stieger, and P. J. Meier. 1990. Expression of the hepatocyte $\mathrm{Na}^{+}$/bile acid cotransporter in Xenopus laevis oocytes. J. Biol. Chem. 265:5357-5360.

6. Hagenbuch, B., B. Stieger, M. Foguet, H. Lübbert, and P. J. Meier. 1991. Functional expression cloning and characterization of the hepatocyte $\mathrm{Na}^{+} /$bile acid cotransport system. Proc. Natl. Acad. Sci. USA. 88:10629-10633.

7. Chomczynski, P., and N. Sacchi. 1987. Single-step method of RNA isolation by acid guanidinium thiocyanate-phenol-chloroform extraction. Anal. Biochem. 162:156-159.

8. Jacobson, A. 1987. Purification and fractionation of poly(A) ${ }^{+}$RNA. Methods Enzymol. 152:254-261.

9. Klein, P., M. Kanehisa, and C. DeLisi. 1985. The detection and classification of membrane-spanning proteins. Biochim. Biophys. Acta. 815:468-476.

10. Devereux, J., P. Haeberli, and O. Smithies. 1984. A comprehensive set of sequence analysis programs for the VAX. Nucleic Acids Res. 12:387-395.

11. Boyer, J. L., B. Hagenbuch, M. Ananthanarayanan, F. Suchy, B. Stieger, and P. J. Meier. 1993. Phylogenic and ontogenic expression of hepatocellular bile acid transport. Proc. Natl. Acad. Sci. USA. 90:435-438.

12. Hediger, M. A., M. J. Coady, T. S. Ikeda, and E. M. Wright. 1987. Expression cloning and cDNA sequencing of the $\mathrm{Na}^{+}$/glucose co-transporter. Nature (Lond.). 330:379-381.

13. Hediger, M. A., E. Turk, and E. M. Wright. 1989. Homology of the human intestinal $\mathrm{Na}^{+} /$glucose and Escherichia coli $\mathrm{Na}^{+} /$proline cotransporters. Proc. Natl. Acad. Sci. USA. 86:5748-5752.

14. Nicoll, D. A., S. Longoni, and K. D. Phillipson. 1990. Molecular cloning and functional expression of the cardiac sarcolemmal $\mathrm{Na}^{+}-\mathrm{Ca}^{2+}$ exchanger. Science (Wash. DC). 250:562-565.

15. Komuro, I., K. E. Wenninger, K. D. Philipson, and S. Izumo. 1992. Molecular cloning and characterization of the human cardiac $\mathrm{Na}^{+} / \mathrm{Ca}^{2+}$ exchanger cDNA. Proc. Natl. Acad. Sci. USA. 89:4769-4773.

16. Carey, M. C., and M. J. Cahalane. 1988. Enterohepatic circulation. In The Liver: Biology and Pathobiology. I. M. Arias, W. B. Jakoby, H. Popper, D. Schachter, and D. A. Shafritz, editors. Raven Press Ltd., New York. pp. 573-616.

17. Hardison, W. G. M., P. J. Lowe, and E. Gosink. 1988. Nature of taurodehydrocholic acid uptake in rat hepatocytes. Am. J. Physiol. 254:G269-G274.

18. Jacquemin, E., B. Hagenbuch, B. Stieger, A. W. Wolkoff, and P. J. Meier. 1991. Expression of the hepatocellular chloride-dependent sulfobromophthalein uptake system in Xenopus laevis oocytes. J. Clin. Invest. 88:2146-2149. 